\title{
The News of Inclusive Education: a narrative analysis
}

\author{
BRUCE DORRIES1 \& BETH HALLER2
}

1Communications Department, Mary Baldwin College, Staunton, VA 24401, USA and 2Department of Mass Communication, Towson University, 8000 York Road, Towson, MD 21252, USA.

\begin{abstract}
This paper investigates a nationally publicised case in the debate over the best method of educating millions of children with severe disabilities. Using Fisher's narrative paradigm, this paper analyses 4 years of the extensive media coverage of the legal battles of Mark Hartmann's family. The 11-year-old's parents took the Loudoun County, VA, Board of Education to court to reinstate their autistic son in a regular classroom. Much media attention focused on the story because it dramatised the issues concerning the national debate about inclusion. The paper provides a synopsis of the narratives about inclusive education within the news media that arose from their coverage of the Hartmann case. Through the press, competing interests told their stories to the public, hoping to win the moral high ground and persuade others of the 'good reasons' that support their understanding of the costs or bene? ts of inclusion. Although the Hartmanns lost in court, this narrative analysis suggests that the family and its supporters provided more persuasive narrative themes in the news media's court of public opinion, thus advancing the national inclusion movement.
\end{abstract}

Inclusive education for disabled children has been a major focus for disability activists and parents of disabled children since the Individuals with Disabilities Education Act (IDEA) became law in 1975. Although a prominent topic in the minds of Americans with school-age children, the issue has only recently begun to attract media attention. News coverage of education issues in general has improved over the years (Hynds, 1989), and with that has come more attention to high-pro? le cases of inclusive education. In 1999, Haller confirmed that in general coverage of disability issues, the news media most often focus on topics related to disabled children $(23 \%)$ and inclusive education (17\%). General education issues were also a popular topic in disability-related stories at $10 \%$ (Haller, 1999).

One explanation for the current news media interest in inclusive education is that 20 years after it was first passed, IDEA was updated and re-authorised in 1997. The result of IDEA has been 
taking disabled children out of institutions and segregated special education settings and integrating them into regular classrooms and school activities. The US Department of Education reports that before IDEA $90 \%$ of children with developmental disabilities received an education in state institutions (US Department of Education, 2000). The Department of Education says that due to inclusive education programmes today, three times the number of people with disabilities attend college and double the number of 20 -year-olds with disabilities are working, when compared to pre-IDEA figures.

However, inclusive education is controversial. When inclusive education programmes were only directed at children with minor learning disabilities, such as slight hearing impairments, the issue was less controversial. However, parents of non-disabled children have long been concerned that children with more severe disabilities, such as autism, can be disruptive to their child's education. Others worry about finite educational resources, if large amounts may be needed for severely disabled children. Studies show that although approximately one third of children in the United States with special education needs receive an education in standard classrooms, few of these children have severe disabilities (Pae, 1994). The controversy has grown as these severely disabled children and their families fight for inclusive education.

One high-profile case rocketed the topic of inclusive education to national media attention in the mid-1990s. Beginning in 1995, Hartmann v. Loudoun County Board of Education tested whether or not schools must include severely disabled children in regular classrooms. Because of their 3-year legal battle in Northern Virginia, the Hartmanns and the inclusion movement became almost synonymous. Mark Hartmann, who is autistic, became a symbol in a national debate over whether, and how often, disabled youngsters should be educated alongside their non-disabled peers (Wilgoren \& Pae, 1994).

Using Fisher's narrative paradigm (1984), this paper analyses 4 years of the extensive media coverage of the Hartmann story to provide a synopsis of the narratives that address the central issues of inclusion. Through the press, competing interests told their stories to the public, hoping to win the moral high ground and persuade others of the 'good reasons' that support their understanding of the costs or benefits of inclusion. Pedagogical issues concerning students with disabilities, who represent $11 \%$ of the school population in the United States, raise complex questions of finance, ethics and academic standards. Varied state standards for the education of disabled children further complicate the discussion. Furthermore, as the inclusion debate continues, the diagnosis of disabled children steadily increases (Lewin, 1997).

Given the importance of this issue and the notoriety of this case, the narratives about Hartmann v. Loudoun warrant scholarly attention. Understanding these narratives also adds to the growing academic analysis of disability discourse (Corker \& French, 1999), which challenges preconceived 'readings' of disability-related texts. Narratives told by the Hartmanns, their 
allies, and the stories of those opposed to inclusion, constitute stories that present 'good reasons' for adopting a point of view (Fisher, 1984). The narratives are more or less persuasive, offering positive values that constitute 'good reasons' to accept a claim. The narrative themes offered by the parties involved in the inclusive education controversy reveal that, although the Hartmanns lost their court battle, their narratives and others on inclusion resonated more persuasively in the news media's court of public opinion, thus advancing the national inclusion movement.

However, before discussing the narrative themes, it is important to note that this article is not an evaluation of inclusive education policy or any educational methods used for disabled children. Instead, this study focuses only on news media narratives about inclusive education as a policy and its implications for the US education system.

\section{The Hartmann Case}

The following section outlines the facts of the Mark Hartmann story as reported by US media, both local and national. After moving from a suburb of Chicago in 1994, Roxana and Joseph Hartmann enrolled their 9-year-old son in second grade at Ashburn Elementary School in Loudoun County, VA. Officials of the northern Virginia school district reported that Mark hit, pinched, screeched and threw tantrums when placed in a standard classroom. Despite having reduced the class size and having an aide work individually with Mark, his behaviour made learning and classroom management problematic, according to school authorities. By the school year's end, officials concluded that the autistic youngster should be removed from a regular class and placed in a Leesburg school with four other autistic students in a 'mainstream' programme. In this type of 'mainstream' programme, the Leesburg school placed students with autism in regular classes only for music, art and gym classes.

Mark's parents refused to accept this decision (Lewin, 1997; Wilgoren, 1994a,b,c). They agreed that their son's experience at Ashburn had been a disaster:

but they blamed the school system for not providing enough training to Mark's teacher and fulltime instructional aide. They pointed to Mark's progress at an Illinois school, where he attended kindergarten and first grade, and they argued that it was crucial to Mark's social development that he go to school with his non-disabled friends (Pae, 1994, C1).

So began a lengthy battle 'that stands as a troubling example of how bitter placement disputes can become' (Lewin, 1997, A1).

The Hartmanns believed the law supported their case. In line with historic American values of equal access to education by all, IDEA was created to guarantee disabled children the right to free and appropriate education in the least restrictive environment (US Department of Education, 2000). Furthermore, an earlier 1988 update of IDEA prevents schools from sending disabled children to special education programmes, such as the one at Ashburn, without their 
parents' permission. However, when Loudoun Country did not receive the Hartmann's approval to remove Mark from a regular classroom, the school district asked the State Supreme Court to appoint a hearing officer to decide Mark's academic future (Rosen \& Jones, 1994). The officer ruled that the boy's educational needs were not served by inclusion and gave school officials permission to transfer him to Ashburn. A spokesperson with the American Federation of Teachers indicated this was the first time any school district was allowed to remove a disabled child from classes since passage of IDEA (Rosen \& Jones, 1994). The Hartmanns appealed.

Although the legal battle had just begun, within months Mark's story had appeared in People magazine, on network morning news programmes and in numerous newspapers as far away as Costa Rica, his mother's native country (Wilgoren, 1994d). During the next 3 years the enmity between the Hartmanns and Loudoun county school district officials took on the character of a difficult divorce (Abramson \& Chadwick, 1997a). Meanwhile, the Hartmanns sought out another public school system that promotes inclusion. First, to enroll Mark in a Montgomery County school in Southwest Virginia, Roxana Hartmann established residence in Blacksburg, VA, and then had to stop a Montgomery County injunction to prevent Mark's enrollment (Devaughn, 1995a,b,c; Washington Post, 1995, February 17). Montgomery County, which has a national reputation for a progressive inclusion programme, lost its argument that the mother and child did not have legal residence status. During the school year the mother and child travelled 250 miles (each way) to be with Mark's sister and father in their North Virginia home on weekends (Wilgoren, 1995).

The family's appeals and lawsuit against Loudoun County continued as Mark successfully settled into school in Blacksburg. Eventually, the case moved to the federal court system (Washington Post, 1995, May 6; Benning, 1996; Estrada, 1996a), where the Hartmanns won a battle. In December 1996, US District Judge Leonie Brinkema ruled that Loudoun County inadequately trained staff to supervise Mark. Her decision was based on evidence that included videotape of Mark in a general education classroom at Kipps Elementary School in Blacksburg, as well as testimony that he had advanced academically and socially at a school in Illinois before the family moved to Virginia (Applegate, 1996a,b; Estrada, 1996b). However, the Hartmanns kept Mark at Kipps in Blacksburg; they chose to wait and see if the case would be appealed by Loudoun. It was, and the 4th US Circuit Court of Appeals reversed the Brinkema decision, ordering the case to be dismissed. The three-judge panel wrote that Brinkema placed too much emphasis on the testimony of advocates for inclusion, rather than school officials (Campbell, 1997).

Finally, the Hartmann's attorney ? led a petition with the US Supreme Court, arguing that Mark's case has significance for the nation (Abramson \& Chadwick, 1997a). Again the story made national news (Suarez, 1997; Abramson \& Chadwick, 1997a,b), but the high court declined to act on the case (Washington Post, 1998, January 14). The Hartmanns, who spent more than $\$ 200,000$ in legal fees arguing for inclusion for Mark (Lewin, 1997), vowed to continue their struggle for the inclusive education movement (Lu, 1998). 
After the legal battled ended, three commentaries, numerous letters to the editor and a lengthy story on inclusion (Applegate \& Lu, 1998) appeared in the major daily newspaper that serves Southwest Virginia, The Roanoke Times. One opponent of inclusion added to the discussion by writing a commentary that said he was:

distressed to read that the recent court decision not to allow autistic and other learningchallenged children into regular classrooms applied to a Northern Virginia school district but not to Montgomery County Schools. In this regard, I recently questioned my daughter about her experiences with such children. Her words were shocking. (Holladay, 1998)

The writer's commentary apparently shocked a number of readers. Over the next month Mark's mother responded to the attack with a long commentary for the paper (Hartmann, 1998), followed by seven letters to the editor supporting her and berating the earlier writer's point of view. The Montgomery County Schools superintendent and school board chairman also contributed a lengthy piece on the issue (Klagge \& Morton, 1998).

The Hartmann v. Loudoun County Board of Education case focused national attention on the inclusive education issue, placing the narratives of competing points of view before the general public. Therefore, the narratives of this case merit closer critical analysis.

Readers may notice one specific narrative is missing from the media coverage - that of Mark Hartmann's own stories told in his own voice. We can only speculate that some of the legal and ethical issues the media face may have caused them to avoid interviewing an autistic person who is not a legal adult. Media law specialists warn journalists that children cannot give legal consent to be interviewed; only their legal guardian can give the consent. Whatever the cause for 'exclusion' of Mark's voice in the coverage of the case, it suggests a significant issue in the discussion about inclusion and education in general: most media stories about any education issue fail to include the 'voices' of those most affected by the issue, children and teens. We suggest this might be a fruitful area of future research, investigating children's own narratives about education that do not appear in the media. However, that topic is not part of the scope of this article.

\section{Narrative Analysis as Method}

Walter R. Fisher's narrative paradigm provides an appropriate methodology to analyse this case study. Narrative inquiry emphasises an interpretive thrust. Interpretive research seeks to expand understanding of how meaning emerges and is used by people in specific contexts. The approach discovers how people create meanings through stories by interpreting their texts. Although there are many methods for conducting narrative analysis, in general the researcher seeks to discover how social actors perceive reality and evaluates the respondents' stories about their reality. Narrative analysis provides critical standards for interpreting stories; it is especially well suited to the study of subjectivity and identity because narrative analysis highlights human agency and imagination (Kohler Riessman, 1993). 
Study of narrative stretches back to the ancients (Foss, 1989), but the most contemporary and extensive work in the field related to this paradigm has been that of Walter R. Fisher (1984, 1985a,b, 1989a,b, 1993). Fisher regards humans as, first and foremost, storytellers-hence, the term Homo narrans identified with the paradigm (Gerbner, 1985). He argues that our reality is composed of sets of stories from which we must choose (Fisher, 1989a). Storytelling is seen as central to all human discourse and interaction. Narratives include all symbolic actions, all 'words and/or deeds - that have sequence or meaning for those who live, create, or interpret them' (Fisher, 1984, p. 2). Our stories aid us in interpreting and understanding our reality, giving meaning to our experiences and creating bonds between those who share stories. Through stories we find order, purpose and guidance in our experience, we create common ground or rapport with others, we establish and maintain cultures.

Fisher's work offers a science of values and an alternative to the rational world paradigm for human communication. He contends that humans as rhetorical beings, or storytellers, are as much valuing as reasoning animals (1989a). Rationality, Fisher maintains, is determined by humans' innate knowledge of narrative probability, i.e. what constitutes a coherent story. Does the story make sense? Does the story conform to guidelines/structure of what constitutes a 'good story'? These basic questions guide our decisions about the reality presented by storytellers. Additionally, humans continually test narrative ? delity, i.e. whether the stories we experience 'ring true' with stories and experiences that we have known in our lives. Reality then is composed of stories from which people must choose in a never-ending process. People make choices based on 'good reasons' which vary in form and according to context. Fisher describes good reasons as those we perceive as:

(1) true to and consistent with what we think we know and what we value, (2) appropriate to whatever decision is pending, (3) promising in effects for ourselves and others, and, (4) consistent with what we believe is an ideal basis for conduct (1989a, p. 194).

Schrag (1991) describes good reasons as a gatekeeper role performed by humans. If warrants for belief or action in a narrative do not meet the criteria listed above, then narrative rationality, Fisher's final tenet, is moot.

Narrative rationality tests narratives that have 'good reasons' against each other to determine which has the 'best reasons'. 'The most compelling warrants for behavior belief', writes Schrag, 'are those with which we most closely identify and, hence, take a more prominent position in our hierarchy of meaningful narratives' (p. 314). Foss (1989) states that narratives, as understood under Fisher's paradigm, enable those who share stories, both the tellers and the listeners, to identify what an experience is about-what is most central to their reality. We connect the central action of a story with our own experience, which helps clarify the central element's significance and we judge narratives' against our own experience, considering if they are complete and consistent. In other words, 'good reasons are the paradigmatic form of human communication and deciding; good reasons are guided by factors like [one's] history and culture ... and the world is constituted from the stories we accept' (Benoit, 1988, p. 535). 
Within this framework, narrative includes 'traditional' forms such as novels or ? Ims, as well as nontraditional forms, such as the content of conversation, an interview or editorials and quotes printed by the media. Schudson notes the shaping of news through use of traditions in narrative, story telling, human interest, etc. This ties into the historical nature of culture.

All of this work recognizes that news is a form of literature and that one key resource journalists work with is the cultural tradition of storytelling and picture-making and sentence construction they inherit, with a number of vital assumptions about the world built in (Schudson, 1991, p. 155).

Within the ritual view of communication (Carey, 1989), news stories are seen as culturally constructed narratives. Within this framework, news still has the power to inform, but Bird \& Dardenne (1988) explain that the information audiences receive is not facts and figures, but a larger symbolic system of news narratives. As a method of communication, news can take on qualities like the myth. Both convey culture. "New stories, like myths, do not "tell it like it is", but rather, "tell it like it means". Thus news is a particular kind of mythological narrative with its own symbolic codes that are recognized by its audience' (Bird \& Dardenne, 1988, pp. 71-72). Bird \& Dardenne assert, therefore, that news narratives provide understanding of the values and symbols in a culture. In this case study, news illustrates cultural narratives about inclusive education.

Fisher's framework has proven useful by enabling scholars to interpret reality, establish connections between people's stories and behaviour, and judge the narratives presented by others for completeness and consistency (Hollihan \& Riley, 1987; Foss, 1989). When applied narrowly, as in the case of this study, the standards for narrative probability and fidelity are useful; 'not so much for testing the argument in a story but for testing its potential credibility with a particular audience and as a test of informal logic' (p. 52). Thus, several of Fisher's concepts offer an interpretive and humanistic approach to the study of communication phenomena.

By emphasising the role of storytelling as central to human existence, the paradigm lends legitimacy to the search for narratives and their meanings in varied social contexts. Stories, the themes they reveal, and their interpretation, are sources of knowledge. Additionally, Fisher's framework encourages the researcher to focus on human values and judgements. The perspective validates the insights of 'naive scientists', as well as the investigator's critical offerings. Similar to practices of critical ethnography, the paradigm encourages reflection. The critic must engage in the process of choosing between conceptual alternatives and making value-laden judgements about meaning and method to challenge the form of human activity (Thomas, 1993).

The characteristics noted above suggest that Fisher's narrative paradigm offers a suitable method to interpret and analyse the narrative themes in the news media coverage of the Hartmann v. Loudoun case, as well as editorials, commentaries and letters to the editor. 


\section{Evaluation of Themes}

Narratives contain key themes that display humans' experiences, as well as their values. Through stories we explain our actions and beliefs, as well as lend meaning to our lives. The stories told in the Hartmann v. Loudoun tale illustrate the tellers' 'good reasons' for supporting inclusion or opposing the practice. In composing stories to explain their life/reality, the tellers make choices based on their 'good reasons'. As noted earlier, good reasons are what the tellers believe to be: (1) consistent with their ideas and values; (2) appropriate to the decisions they had to make; (3) beneficial to themselves and others; and (4) consistent with what they believed was an ideal basis for conduct (Fisher, 1989a). In other words, the narratives aided the tellers in interpreting and understanding their reality, giving meaning to their experiences and creating bonds with those with whom they shared the stories.

This section presents brief narratives and the good reasons embedded in themes drawn from press coverage of the Hartmann v. Loudoun case. In an effort toward brevity, this paper examines eight themes that evolved from the inclusive education debate in the Hartmann case. Themes were embedded in the stories told by the actors in this social drama. They expressed 'something that people believe, accept as true and valid; it is a common assumption about the nature of their experience' (Spradley, 1979, p. 186). The themes presented here have a high degree of generality. Although themes were not counted to determine frequency, they recurred in the media coverage of the case and in editorial comments. When participants expressed a single idea, at different times, in different settings, through similar stories, this suggested a possible cultural theme. Cultural themes are known and used by people to organize their behavior and interpret experience, even if they cannot express them with ease.

Offered here are themes that were chosen and created in keeping with interpretive, socialconstructionist practices (Gergen, 1985; Larkin, 1986; Kohler Reissman, 1993). No doubt others gathering data from the same stories might create different themes to describe and characterise the Hartmann v. Loudoun case. The process of identifying narrative themes began after more than 90 news stories, editorials, commentaries, letters to the editor and three radio transcripts about the case were gathered and analysed. The media stories came from a variety of sources, but most prominent were The Roanoke Times, Richmond Times Dispatch, The New York Times, The Washington Post, National Public Radio's (NPR) 'Morning Edition' and 'Talk of the Nation'. After achieving an understanding of the case, the social/moral arguments surrounding inclusion, and examining the narratives over time, the narrative themes began to reveal themselves. After common ideas and experiences were highlighted within the narratives, categories were created to characterise the narratives likely to increase readers' understanding of the moral arguments.

The themes are divided into those that support the Hartmanns or inclusion, and those that support the Loudoun School District or are against inclusion. (Four narrative themes each.) This division over-simplifies the nature of the public discussion about inclusion; there are more than two sides to this complex issue. However, this division provides a more concrete, linear way to 
discuss the narratives and themes. The themes found in narratives told by the Hartmann's and inclusion supporters include:

\section{Narrative Theme 1: Everyone Wins with Inclusive Education}

This narrative connects to an overarching theme imbedded within the IDEA legislation - that inclusive education benefits disabled children in the short run with better learning and, in the long run, with more employment and post-secondary educational opportunities. The benefit of inclusive education for nondisabled children is the ability to understand and cope with a more diverse society and people who are different from themselves.

For example, a New York Times analysis piece on inclusive education embraces the narrative of IDEA that it benefits all children, not just those with disabilities:

Many educators and parents believe that segregating children with disabilities is bad, both educationally and morally. They say such a policy undermines the development of both disabled children, by failing to give them a chance to develop the skills and relationships that they will need as adults, and other children, by preventing beneficial contact with the full range of people in their communities. (Lewin, 1997, p. 20)

Mark Hartmann's mother, Roxana, most often provides this 'everyone wins' narrative, in both her quotes to media and her Roanoke Times commentary on her son's case. In the following narrative from her commentary, she explains the benefits of inclusive education for all children:

... (Mark) has demonstrated that there are no long-term harmful effects on the classmates of a disabled child. In fact, full inclusion gives them an opportunity to embrace diversity and grow in compassion and understanding-honorable goals that will serve our children well through their lifetime. In sum, through inclusion, we can make our communities a better place for people with disabilities one child and one family at a time, if we work together. It's the best thing to do for our future together. (Hartmann, 1998, A7)

Roxana Hartmann's quotes for the newspaper explain also the difference inclusion made for Mark in terms of his less volatile behavior specifically:

'He understands language. I can talk to him like I can talk to you. I don't have to speak differently,' Hartmann explained. The other day it was raining and I didn't feel like taking him swimming, so I said to him that I didn't want to go. He just waved his hand a little, saying we didn't have to go. There was no screaming, no tantrums. (Lu, 1998, A1)

Joseph Hartmann, Mark's father, presented this same narrative nationally when he was part of a NPR 'Morning Edition' story on inclusive education:

JOSEPH HARTMANN: He's becoming able to cope in society as society is, with his peers in the classroom. He knows when his teacher says: 'OK, class, everybody be quiet' that it is his job to be quiet. He knows when the teacher says: 'OK, class, it's time to go to lunch,'- 'OK, I've got to get my lunch box and stand in line with everybody else and go on ... 
' If you have him in an autistic class, three or four other autistic kids, and they sit around and play with blocks all day, you don't take them out into the world except to visit (Abramson \& Chadwick, 1997b).

The news media also relied on prominent pro-inclusion sources, which made the narrative compelling. In articles about the broader inclusive education topic, such as the following New York Times article, Judith Heumann, an assistant secretary in the Office of Special Education and Rehabilitative Services at the US Department of Education, who is herself a wheelchair user, explains the 'everyone wins' narrative in a national community context:

'Education is academic, but it's also social, learning how to live in a community, learning about differences,' she said. 'I tell parents who are afraid to send a child with disabilities into a regular setting that overprotection does no service when that disabled child becomes an adult. If your child was out of sight, out of mind, that doesn't change. People who might have become their friends in school won't know them.'

Academically, too, she said, all children can benefit from inclusion. '

The methods that teachers learn from working with the disabled and individualizing instruction, are useful with other students, as well,' Ms. Heumann said. 'In a way, you can see every child as having special needs. So the ideal is a system in which every child gets an individualized education'. (Lewin, 1997, p. 20)

The narrative takes on even more strength when adults with disabilities, who were the product of inclusive education, enter the discourse. The following was a letter to the editor in The Roanoke Times, written after a commentary disparaged the benefits of inclusive education:

I have cerebral palsy and a hearing impairment. I spent most of my school years in 'regular' schools in Connecticut in the 1960 s and 1970 s, so I am a product of inclusion. I shudder to think what I would have become had I not been given the challenges and intellectual and social stimulation I received. It motivated me to get a good education and to try to make a difference in the world.

The parents of children with disabilities in Montgomery County only want what I was given. These children are more likely to learn appropriate behavior if they are 'included' in regular classes. Able-bodied children learn about acceptance, tolerance and compassion toward those who are 'different', and perhaps something about 'the power of the human spirit'. Not all education is gained from books and facts. Holladay's misconceptions tell me we still have a long way to go toward understanding and accepting people with disabilities. (Vass-Gal, 1998, A7)

These letters to the editor from disabled people ? t with Swain \& Cameron's notion of 'coming out' for disabled people (1999). They say that when people embrace their social identity as disabled persons, they begin challenging oppression and 'campaigning for equal opportunities to access education, employment, transport, housing, leisure facilities and control over personal lives' (Swain \& Cameron 1999, p. 76). The narratives from disabled people who are 
proud of their identity have even stronger resonance because their success demonstrates the potential for Mark Hartmann to grow into an adult with a positive self-concept.

\section{Narrative Theme 2: Inclusion is Cheaper}

This narrative appears in two ways. One implied theme is that society benefits in general from inclusive education because well-educated disabled children mean future contributing, taxpaying members of society, rather than tax burdens. However, typically, the narrative was more overt: inclusive education costs less than institutionalisation of severely disabled children.

Roxana Hartmann makes the argument that institutionalisation is expensive and has long-term costs for society.

But the commonwealth does support large institutions. A large chunk of your tax dollars are spent in institutions. It costs more than $\$ 80,000$ per year to support a person in an institution, and it's getting more expensive all the time. By the year 2000, the national average will reach $\$ 113,000$ per person in an institution. There are 189,000 Virginians with mental retardation alone-the greater majority housed in institutions. But why is this relevant to the education of a disabled child?

We know from experiences of our sister states that it all begins with decisions focused on educating the disabled child. Early-intervention strategies and an inclusive education posture are proven as an effective approach to integrate our disabled citizens into the community with jobs that they can be trained for and normal home settings to live in. Community-based living and care works better than institutions, and costs far less. (Hartmann, 1998, A7)

The message from the US Department of Education about IDEA is similar. It estimates that educating students in neighborhoods, who would previously have been institutionalised, saves $\$ 10,000$ per child (US Department of Education, 2000). Consistent with notions of American pragmatism, this narrative ties to capitalistic notions of 'the bottom line', in which citizens embrace policies that reduce taxes or give the most benefit for the least amount of tax dollars.

\section{Narrative Theme 3: Human Rights Should Apply to Everyone in a Civilized Society}

Typically, this narrative is tied to every American's right to a free public education. The right to an education is presented as a human right available to all equally. Roxana Hartmann puts it succinctly:

After contemplating this response, I have decided to review some facts that may be overshadowed by accusations (real or imagined) and that may not be obvious to a casual observer.

First of all, public education is the right of all children. The Individuals With Disabilities Act guarantees access for disabled students into the 'least restrictive environment.' The only measure is that the school must demonstrate that the disabled child is able to learn in the LRE with appropriate support, services and accommodations. 
... In all our debate, we should remember that each and every child in our community including the disabled, is a valued human being who has a basic right to opportunity-whether we are talking work, education, housing or access to public buildings. To consider it otherwise will take us back to the 1860s. (Hartmann, 1998, p. A7).

Several members of the local southwestern Virginia community continue the free and public education narrative in a number of letters to The Roanoke Times:

How does Holladay justify saying that his daughter has more of a right to an education than my brother? Holladay is concerned about students who 'can learn algebra and Spanish, children for whom the schools are intended, and whose futures will depend on what they learn now.' All children's futures are determined by what they learn. This is a public school system, and everyone has a right to an education. (Greenberg, 1998, p. A7)

Our community has chosen (inclusion) for more than 10 years, with all its pitfalls, challenges and magic, because we care about children. All children have a future, and, in America, schools are intended for everyone. (Bickley \& Bickley, 1998, p. A7)

Public schools aren't for the learning elite. They are public schools, and by law must provide an appropriate education in the least restrictive environment for all children. There is no such thing as separate but equal. (Eaton, 1998, A7)

Although an explicit link is not made in the statements, the theme within these statements is reminiscent of the education reforms that African Americans fought for in the 1950s and 1960s to bring about integrated public education for black and white children. The inclusion movement puts forth the same notion, that separate but equal does not fit with American ideals.

\section{Narrative Theme 4: Inclusive Education has Proven itself}

Specifically, this narrative tied into Mark Hartmann's success in an inclusive Downloaded by [Towson University] at 15:06 27 October 2015 Inclusive Education 883 education environment before moving to Virginia and, broadly, the success of such programmes nationally and in Blacksburg, VA, where Mark Hartmann was placed early in the case. For example, Jamie Ruppman, an education consultant who works with disabled children, saw Mark's success back in Illinois destroying the case of Loudoun County. Educators from Illinois did testify that Mark was successful in their inclusion program before the family moved to Virginia (DeVaughn, 1995a).

As Roxana Hartmann explained: 'All you have to know about this case is that Mark was successfully included in Illinois and in Montgomery County. The only place he could not be successfully included was Loudoun County, and that's clearly because the school system did not have the commitment to do it' (Benning, 1997b). Hartmann continued this argument by explaining why she chose to move to Montgomery County: '[That county] is one of the few 
school districts in Virginia to honor and abide by IDEA - the law. Among other states, Virginia is ranked 46th in its support of people with disabilities and their families' (Hartmann, 1998, p. A7). Others made similar arguments.

'I have heard nothing negative about having this child stay', the president of the Montgomery County Council of PTAs said. 'What I have heard is: Why did the school system take a negative stand against this child in the first place? From a parent standpoint, this woman did everything she could for her kid (in Loudoun County), then set out to find what she could for him somewhere else.'

... We need to show that it works so other school systems can try to do the same thing. (DeVaughn, 1995b, p. A1)

The successful inclusive education program narrative is also connected specifically to Mark's educational growth. Roxana Hartmann says: 'He has blossomed in a very nurturing environment here with people who are dedicated and understand him and his disability. He'll stay here until he finishes school' (Lu, 1998, p. A1). The Timmy Clemens case also bolsters the narrative of inclusive education 'proving itself':

Four years ago, Timmy Clemens could not walk near a classroom without becoming so scared he couldn't enter the room. His autism required a full-time aide and much patient coaxing to get him through a day.

By his senior year last year, Timmy could walk to classes in Blacksburg High School on his own. With the help of his aide, Marc Eaton, and a special board that lists the alphabet and short words such as 'yes' and 'no', he did homework and took tests in courses such as algebra and honors history. Today, as a postgraduate, he works with an aide in a job at Blacksburg's Municipal Building.

'Some truly believe in it; some think it's a waste,' said Judy Clemens, Timmy's mother. But other people's opinions don't matter, she said, because she can see the improvements in her son.

I don't think inclusion is perfect. But I think it's going to get better and better, and I'm proud of Montgomery County. (Applegate \& Lu, 1998, p. A1)

Although these narrative themes in the Hartmann case advanced the cause of inclusive education, many who opposed the Hartmann arguments and/or inclusion were included in media coverage or wrote commentaries against the issue. Their oppositional narratives suggested the following themes:

\section{Narrative Theme 5: Not in My Kid's School}

This narrative presupposes that inclusive education will always have a disruptive effect on nondisabled children in the classes and therefore should not be allowed. It is based on some anecdotal reports that a few severely disabled children, such as those with autism, have been 
disruptive. However, there is also much anecdotal evidence of disruptive non-disabled children, which is rarely mentioned in anti-inclusion narratives.

One parent, Steve Holladay, a Blacksburg, VA, parent, stated this narrative through his commentary piece in The Roanoke Times. The Virginia Tech professor claimed to quote his daughter, whose words were 'shocking': Many of these children (inclusion students) are uncontrollable. They enter your classroom in the middle of a class, and it may take 15 minutes for their aide to return them to the classroom they are assigned to. They break into loud crying fits or other noise making episodes regularly, at unpredictable times and without apparent cause, bringing a halt to teaching until control is re-established.

They wander around the class while the teacher is trying to teach, sometimes selecting a student to sit with and engage in an up-close, face-to-face staring contest. They may unexpectedly slap you in the forehead when you walk by them in the hall ...

It cannot be denied that many of these children are extremely disruptive. And if they have been found to be too disruptive for normal classrooms in other school districts, why do we place them in our classrooms where our children have their only opportunity to learn many foundational concepts? Do they magically behave better here? ... Montgomery County has become an island that will accept highly disruptive children into our schools, children impaired to the point of being totally oblivious to the educational process going on around them, children incapable of learning in any way marginally related to the original intent of the school's programs, or to the expectations placed on other children in the classrooms. (Holladay, 1998, p. A7)

Other parents present this narrative of the disruptive effect of inclusive education. Even the mother of an autistic child wrote:

I am the mother of an autistic child, and I agree with Steve Holladay ... I do believe in mainstreaming, where the child is placed in a regular classroom for short periods of time and gradually works up to a full class period. With mainstreaming, 'normal' children get the education they deserve and need without disruption by our 'learning-challenged' children. (Kingery, 1998, p. A7)

A teacher continued the narrative of disruptive inclusion kids.

'Our biggest problem is putting up with emotionally disturbed kids when they are disruptive and distracting to other children,' she said. 'That's a waste of time and that's where we're losing ground.'

Hall, [a] language arts teacher, also resents having to design different tests and notes and other material for some students and fears it inevitably watered down the lesson for all students.

(Applegate \& Lu, 1998, p. A1)

\section{Narrative Theme 6: Protect the Sensitive 'Normal' Students}


Those who question inclusion also argued that it may be traumatic for non-disabled children to be in the presence of severely disabled children:

Beyond lost education, what effect might this have on the sensitive child who isn't yet ready to experience this type of behavior and instability?

I am sincerely sympathetic for Ms. Hartmann and her situation, and very thankful that my own children are healthy. I further admire her obvious determination to provide what she believes to be the best growing and learning environment possible for her son. However, she and others who move here to take advantage of our inclusion policy seem to have little concern about the effect their children may have on other children in the classrooms.

... Does Ms. Hartmann care about the boy or girl who sits in front of the inclusion child during the uncontrollable screaming fit? What about the child whose personal space is invaded by stares or inappropriate touching? Or my own daughter, who receives a stunning slap on the forehead out of the blue?

I asked other adults for their views about our inclusion policy. Not one spoke positively about it. One individual told of a girl whose earring was torn off by an inclusion child, and who subsequently was terrified of going to school. Another said her son quit Scouts because an inclusion child had selected him to shadow and touch. (Holladay, 1998, p. A7)

The mother of an autistic child adds to the narrative, believing her son's behaviour might upset other children. 'He couldn't tolerate all the activities and stimulus, nor would it be fair to the other children in the classroom' (Kingery, 1998, p. 7A).

\section{Narrative Theme 7: School is about Academics}

In contrast with the inclusive education argument that it bene? ts children in many more ways than just academics, those opposed to the practice argue schools are to provide an education in reading, writing, arithmetic, etc. The attorney for Loudoun County illustrates this narrative in her comments to NPR's Morning Edition:

KATHLEEN MAYFOUD, ATTORNEY FOR LOUDOUN COUNTY, VIRGINIA SCHOOLS: Socialization is part of that, but academic and educational instruction is obviously the primary responsibility. So, Loudoun would have had to totally overlook the educational requirements in favor of a minor goal (Abramson \& Chadwick, 1997b).

Holladay ties the idea of a proper learning environment with this narrative and argues that inclusive education is its antithesis.

Doesn't it seem obvious that loss of teaching time to disruptive or ongoing distractive behavior isn't conducive to learning?

Similar to Ms. Hartmann, we (the other parents) are also determined to provide our children the best possible learning environment. As an educator myself, I don't like our inclusion policy. I 
would never tolerate such disruption in my classrooms unless, as has become the case in Montgomery County, I was mandated to do so by law.

I truly do care about Mark. However, I care more about his classmates who can learn algebra and Spanish, children for whom the schools were intended, and whose futures will ultimately depend on what they learn now. (Holladay, 1998, p. A7)

\section{Narrative Theme 8: Attendance is not the same as Integration}

This narrative questions definitions of inclusive education. It also re-interprets various aspects of inclusive education as having a negative effect. For example, Richard Schattman, a Vermont principal who believes in inclusion, explains how inclusion, when poorly implemented, gives those opposed to inclusive education fodder to urge for its dismantling. 'A student can be more isolated and segregated in a normal classroom than in special education,' Mr Schattman said. 'Inclusion isn't about placing the kid. It's about making the placement successful both for the kid and for the rest of the class. And it's not easy. You need small classes, lots of planning time, and staff that believes in it.'

Some special education experts worry that the inclusion movement may lead to dumping children with special needs into classes where they will be ignored or taunted, and eliminating the special services and support that they receive in settings intended just for them.

'It has not been demonstrated that regular classrooms, even fortified regular classrooms using the best practices can accommodate all children all the time,' said Douglas Fuchs, a professor of special education at Vanderbilt University. 'The full inclusionists honestly believe that creating a situation in which teachers individualize instruction for each student is a terrific goal we should all dedicate our lives to. So we should kick away the crutch of special education. But that's a high stakes game, and I'm not sure it's realistic.'

Nor are all parents and advocates for children with disabilities convinced that it is the correct goal. (Lewin, 1997, p. 20)

This narrative supports those opposed to inclusion by noting that it may not be the right accommodation for every disabled child. This type of theme turns inclusive education on itself, i.e. because it may not be appropriate for all disabled children, maybe be it should not be used at all. The New York Times story above continued this narrative by explaining that because of disruptive, abusive, and violent children, Vermont, the premier state for successful inclusive education, is placing such children in separate settings (Lewin, 1997).

\section{Conclusions and Discussion}

As noted in this analysis, narrative themes were divided into those that support the Hartmanns/inclusive education and those that do not. This reflects a problem that is imbedded within the debate itself, by creating a division that oversimplifies the nature of inclusive education. The public discussion about this case reflects standard news coverage of a 
controversial issue- 'either-or' dichotomy, debate rather than discussion (Tannen, 1998). When the news narratives follow lines of 'yes' or 'no' about inclusive education, they miss an opportunity to critically assess the issue for all children in US public school systems. When the focus is on a two-sided debate, rather than a multi-faceted discussion, the news media are also more likely to drop coverage of the topic if one side of the debate tires of presenting their narratives.

The media stories and commentaries, and the themes they illustrate about inclusive education, lend insight into the participants' beliefs, actions and world views, as well as their conflicts of opinion and perception relative to the setting (Hollihan \& Riley, 1987). Although this paper touched on just a few of the prominent themes about inclusive education in the news, we believe the themes offered in this paper dominate the discussion. Furthermore, we conclude that even though some parents of nondisabled children are vehemently opposed to inclusive education, it was the more numerous and more vocal parents of severely disabled children, educators, and proponents of IDEA who set the tone of the debate and framed inclusion as a workable approach to educate disabled children. We conclude that though the Hartmanns lost their case against Loudoun County, the narratives they inspired actually won in the court of public opinion.

It has taken almost 25 years for pro-inclusion narratives to take hold. As programmes in Montgomery County, VA, Illinois, and Vermont show, school districts need not only well-trained faculty and well-? nanced programmes to succeed, but public support as well. For example, when parent Steve Holladay wrote to criticise inclusive education in Montgomery County, VA, his criticism was met with seven letters to the editor positively endorsing inclusive education. In the pro-inclusion environment of Montgomery County, VA, the local newspaper, The Roanoke Times, seemed to present the proponents' narratives wholeheartedly. Even when the Hartmanns lost their case, the newspaper published a family-provided colour photo of Mark Hartmann on its front page (Lu, 1998). In the photo, Mark Hartmann, wearing T-shirt and shorts, grins broadly as a picture-perfect 'average' kid. The image alone provides a 'good reason' that Mark should be in a regular classroom because he is presented visually as a 'regular kid'. Earlier, the newspaper published a large 2-page spread on inclusive education in the county, providing a location for thoughtful discussion of the issue and primarily 'good reasons' for inclusive education.

Some opponents of inclusive education fear the public and policymakers may be swayed by an underlying message of pity for the 'poor, little disabled children'. The conservative National Journal feared during the re-authorisation of IDEA in 1997 that:

Overhaul of the Individuals with Disabilities Education Act is tailor made for policy decision by anecdote. The facts and figures are sparse and conflicting; the horror stories are stark and vivid. And the interest groups are well organized, disciplined and loaded with heart-tuggers or spinechillers, depending on their legislative goal. 
In the past, organizations representing the disabled could count on their substantial political clout in Congress. 'Politicians are terrified of them - that they'll trot out people in wheelchairs,' a lobbyist for an education organization said enviously. 'It's very easy for a Member to feel virtuous voting for their issues'. (Stanfield, 1995)

Yet the findings from this narrative analysis illustrate that proponents of inclusive education have no need to trot out hackneyed, pity images of disabled children. They rely on much stronger and more salient narratives: inclusion is a win-win situation for everyone; public education is every child's right; inclusion is cheaper than institutionalisation; and inclusion has proven itself successful nationally. These 'good reasons' hold the most persuasive power because they appeal to the audience's general understanding of equality and humanity, which most Americans embrace. As one woman with cerebral palsy and a hearing impairment explained the good reasons from her personal inclusion experience: Disabled 'children are more likely to learn appropriate behavior if they are "included" in regular classes. Able-bodied children learn about acceptance, tolerance and compassion toward those who are different, and perhaps something about "the power of the human spirit." Not all education is gained from books and facts' (Vass-Gal, 1998, p. A7).

These themes/stories in support of inclusion are consistent with American values of equalitythe country has determined that schools cannot be separate and truly equal. Furthermore, the effects of inclusion, while perhaps detrimental to a few students, largely have promising effects for both students with and without disabilities. Inclusion represents Fisher's notion of a powerful narrative being representative of an ideal basis for conduct. While many of the stories against inclusion suggest pragmatic or traditional bases for educational policy, readers of the narratives are likely to ? nd the rationality of the pro-inclusion arguments more consistent with US history and culture. For example, the 1960s civil rights movement, which successfully dismantled separate, but unequal educational systems for blacks and whites suggest the type of ideal conduct to which Fisher refers. The civil rights movement forced the United States to once again acknowledge the central narrative of its founding - that all citizens are created equal and deserve equal opportunities in all aspects of US society, including education.

Although the narratives evaluated in this study were only linked to the media coverage of inclusive education, we believe another area of inquiry could involve comparing coverage of this movement for disabled children with narratives reported in media about desegregation of US schools in the 1960s and 1970s. Would narratives from both movements support the same or similar themes? US history tells us that some of the same arguments and cultural values were employed during that period of change in US educational policy. For example, some of those who were against the integration of black children into predominantly white schools made some arguments parallel to those opposed to inclusion: that desegregation would be disturbing to both black and white children, that it would be disruptive to the academic process, that schools were for academics not socialisation, and that some students were not 
served by desegregation. Our conclusion is that just as these anti-integration narratives proved less persuasive in the 1960s, the narratives against inclusion are becoming less effective today.

After the loss of her son's case, Roxana Hartmann said she will continue to lead national discourse about inclusive education: ‘

This is the end, but it's not going to stop me from talking about inclusion,' Roxana said. 'No, if anything, it's made me more of a believer than ever' ... 'This is not about winners and losers; this is about schools doing the right thing for the children,' she explained. (Lu, 1998, p. 1A).

Widespread media coverage of Hartmann's narrative and those of other supporters of inclusion should also prove to help make others believers in the movement's aims.

\section{REFERENCES}

ABRAMSON, L. \& CHADWICK, A. (1997a, Nov. 6) Disabilities, Morning Edition (transcript \# 97110611-210).

ABRAMSON, L. \& CHADWICK, A. (1997b, Nov. 7) Mark Hartmann: Part II, Morning Edition (transcript \# 971101709-210).

APPLEGATE,L. (1996a, Dec. 6) Autistic child can go back to Loudoun school, judge says, Roanoke Times, p. B1.

APPLEGATE, L. (1996b, December 7) For autistic boy, school's open, Roanoke Times, p. B1. APPLEGATE, L. \& LU, K. (1998, February 1) Seeking best place to learn, Roanoke Times, p. A1.

BENNING, V. (1996, May 20) Autistic boy doing well, Washington Post, p. B3.

BENNING, V. (1997, July 10) Court backs decision to remove autistic boy from regular class, Washington Post, p. D1.

BENOIT, W. (1988) Review of human communication as narration: toward a philosophy of reason, value and action, Argumentation, 2, pp. 535-538.

BICKLEY, S. \& BICKLEY, P. (1998) Community supports inclusion policy [Letter to the Editor], Roanoke Times, p. A7.

BIRD, S.E. \& DARDENNE, R.W. (1988) Myth, chronicle, and story, in: J.W. CAREY (Ed.) Media, Myths, and Narratives, pp. 67-86 (Newbury Park, CA, Sage).

CAMPBELL, T. (1997, July 9) Suit on mainstream dismissed, Richmond Times Dispatch, p. B. CAREY, J. (1989) Communication as Culture (New York, Routledge).

CORKER, M. \& FRENCH, S. (1999) (Eds) Disability Discourse (Buckingham, Open University Press). DEVAUGHN, M. (1995a) Autistic pupil not welcome, Roanoke Times and World News, p. A1. DEVAUGHN, M. (1995b, February 17) Judge hears from autistic boy's mom, school board, Roanoke Times \& World News, p. B1. 
DEVAUGHN, M. (1995c, March 4) Judge lets autistic boy attend Montgomery school, Roanoke Times and World News, p. A1.

EATON, M. (1998) Inclusion can help all students, Roanoke Times [Letter to the Editor], p. A7. ESTRADA, L. (1996a, September 10) Parents' suit seeks to return autistic son to Loudoun School, Washington Post, p. B5.

ESTRADA, L. (1996b, December 6) Loudoun must mainstream autistic boy, Washington Post, p. A1. FISHER, W.R. (1984) Narration as a human communication paradigm: the case of public moral argument, Communication Monographs, 51, pp. 1-22.

FISHER, W.R. (1985a) The narrative paradigm: 'In the beginning', Journal of Communication, 35, pp. 74-89.

FISHER, W.R. (1985b) The narrative paradigm: an elaboration, Communication Monographs, 52, pp. 347-367.

FISHER, W.R. (1989a) Human Communication as Narration: toward a philosophy of reason, value, and action (Columbia, SC, University of South Carolina Press).

FISHER, W.R. (1989b) Clarifying the narrative paradigm, Communication Monographs, 56, pp. 55-58. FISHER, W.R. (1993) When teaching 'works': Stories of communication in education, Communication Education, 42, pp. 279-281.

FOSS, S.K. (1989) Rhetorical Criticism: exploration and practice (Prospect Heights, IL, Waveland Press). GERBNER, G. (1985) Homo narrans: story-telling in mass culture and everyday life, Journal of Communication, 35, p. 73.

GERGEN, K.J. (1985) The social constructionist movement in modern psychology, American psychologist, 40, pp. 266-275.

GREENBERG, L. (1998) Everyone has a right to go to public schools, Roanoke Times [Letter to the Editor], p. A7.

HALLER, B.A. (1999, July) News Coverage of Disability Issues: a final report for the center for an accessible society (San Diego, CA, Center for an Accessible Society).

HARTMANN, R. (1998, February 16) My son's right to an education doesn't hurt others, Roanoke Times, p. A7.

HOLLADAY, S. (1998, February 7) Learning-challenged kids shouldn't be in regular classrooms, Roanoke Times, p. A7.

HOLLIHAN, T.A. \& RILEY, P. (1987) The rhetorical power of a compelling story: a critique of a 'Toughlove' parental support group, Communication Quarterly, 35, pp. 13-25. 
HYNDS, E.C. (1989) Survey finds large daily newspapers have improved coverage of education, Journalism Quarterly, pp. 692-696, 780.

KINGERY, D. (1998) Mainstreaming can be done gradually [Letter to the Editor], Roanoke Times, p. A7. KLAGGE, J. \& MORTON, F. (1998, March 13) Balancing the needs of special and regular students, Roanoke Times, p. A9.

KOHLER RIESSMAN, C. (1993) Narrative Analysis (Newbury Park, CA, Sage Publications). LARKIN, T.J. (1986) Humanistic principles of organizational management, Central States Speech Journal, 37 , pp. 36-44.

LEWIN, T. (1997, December 28) Where all doors are open for disabled students, New York Times, p. A1 LU, K. (1998, January 14) Autistic pupil loses fight to be 'included', Roanoke Times, p. $1 \mathrm{~A}$.

PAE, P. (1994, December 16) Loudoun can take autistic boy out of regular class, Washington Post, p. C1. ROSEN, M. \& JONES, R. (1994, Oct. 17) Odd child out, People, p. 113. SCHRAG, R. (1991) Narrative rationality and 'first stories': pedagogical implications for children's television, Communication Education, 40, pp. 313-323.

SCHUDSON, M. (1991) The sociology of news production revisited, in: J. CURRAN \& M. GUREVITCH (Eds) Mass Media and Society, pp. 141-159 (London, Edwin Arnold).

SPRADLEY, J. (1979) The Ethnographic Interview (New York, Holt, Rinehart \& Winston). STANFIELD, R. (1995) Tales out of school, National Journal, 27, pp. 33-34.

SUAREZ, R. (1997, November 17) Inclusion, Talk of the Nation (transcript \# 97111701-211).

SWAIN, J. \& CAMERON, C. (1999) Unless otherwise stated: discourses of labelling and identity in coming out, in: M. CORKER \& S. FRENCH (Eds) Disability Discourse, pp. 68-78 (Buckingham, Open University Press).

TANNEN, D. (1998) The Argument Culture (New York, Random House). THOMAS, J. (1993) Doing Critical Ethnography (Newbury Park, CA, Sage Publications).

US DEPARTMENT OF EDUCATION (2000) Overview of IDEA. [Available On-line]. http:// www.ed.gov/offices/OSERS/IDEA/.

VASS-GAL, S. (1998) Parent's worries reflect misconceptions [Letter to the Editor], Roanoke Times, p. A7.

Washington Post $(1995$, February 17, 1995) Loudoun parents seek new school for autistic son, p. D3. Washington Post (1995, May 6) Finding on autistic boy upheld, p. B2. Washington Post (1998, January 14) Loudoun disability case won't be heard, p. B3. 
WILGOREN, D. (1994a, August 16) Loudoun wants autistic boy out of class, Washington Post, $p$. B1. WILGOREN, D. (1994b, October 28) Mother says regular school is crucial for autistic boy, Washington Post, p. B3.

WILGOREN, D. (1994c, December 8) Ruling due on boy's schooling, Washington Post, p. VI, Virginia Weekly section.

WILGOREN, D. (1994d, December 27) In autism case, hearing is over, but battle isn't, Washington Post, p. D1.

WILGOREN, D. (1995, March 11) Autistic Loudoun boy enters school in SW VA, Washington Post, p. B2. WILGOREN, D. \& PAE, P. (1994, August 28) As Loudon goes, so may other schools, Washington Post, p. B1. 